\title{
Experiência pedagógica no progressismo desenvolvida em 1969 na llha de Paquetá
}

\section{José Augusto Di Jorge Vasconcellos}

Professor de Biologia do Estado do RJ, membro do Conselho Editorial da Revista Ciência \& Luta de Classes do Centro de Educação Popular e Pesquisas Econômicas e Sociais Especialista em Educação pela UERJ, Rio de Janeiro, Brasil

\section{Maria Júlia da Costa Belém}

Professora titular de Zoologia do Instituto de Biologia da UFRJ, Mestre em Zoologia pela UFRJ, Rio de Janeiro, Brasil

\section{Resumo}

O artigo expõe a aplicação da filosofia pragmática de John Dewey no estudo da fauna marinha da ilha de Paquetá, feito por alunos da escola secundária com orientação dos professores, em 1969. O desenvolvimento do projeto modificou a prática do estudo de Zoologia do imobilismo para um processo de compreensão da adaptação dos animais nos seus ambientes na elaboração de chaves de classificação, que permitiram aos educandos compreender que a evolução das espécies é um processo.

Palavras-chave: contexto, projeto-escola, cadeia alimentar, sobrevivência.

\section{Abstract}

The article shows pragmatic philosophy of John Dewey on study of sea fauna of Paqueta Island, done by students of high school with direction of teachers in 1969. The development of the project transformed the practice of study of zoology of immobilism to comprehensive process of the adaptation of animals in their habitats in the working up of classification keys, which allow to the student understand that species evolution is a process.

Keywords: context, school project, food chain, survival.

\section{Resumen}

El artículo expone aplicación de la Filosofía Pragmática de John Dewey en el estudio de la fauna marina de la isla de Paquetá hecho por los estudiantes de la escuela secundaria con orientación de los profesores en 1969. El desarrollo del proyecto cambió la práctica del estudio de Zoología del inmovilismo del alumno hacia un proceso de comprensión de la adaptación de los animales en sus medios, a través de la elaboración de llaves de clasificación, que permitirán los educandos tener comprensión de que la evolución de las especies es un proceso.

Palabras llave: contexto, proyecto-escuela, cadena alimentar, supervivencia 


\section{I - INTRODUÇÃO}

A concepção filosófica pragmatista estabelece que a aprendizagem seja fundamentada na motivação, no interesse e curiosidade do aprendiz.

O processo de aprendizagem ocorre através da resolução de problemas, possibilitando ao educando reconstituir e reinterpretar as suas próprias experiências.

O pragmatismo opõe-se às verdades absolutas, nas quais os alunos são vistos como produtos imutáveis dos valores escolásticos e sincréticos de uma sociedade tradicionalmente oligárquica e preconceituosa.

A educação na filosofia pragmatista é na realidade um processo e não simplesmente um produto, o que possibilita aos discentes enfrentar problemas atuais e futuros em um nível de compreensão libertos dos dogmas impeditivos da elaboração de novas ideias e concepções, tornando-os melhores seres sociais, através do uso do método experimental e da análise filosófica com base na dialética de Hegel, possibilitando torná-los seres capazes apenas de compreender o tempo histórico enraizado na realidade democrática e liberal burguesa.

A sociedade em que John Dewey nasceu e desenvolveu suas reflexões sobre a problemática educacional norte-americana é uma sociedade de classes onde o poder político representa as grandes corporações financeiro-agro-industriais cujos os interesses estão voltados para a proteção das classes dominantes. A escola é o microcosmo da sociedade na qual ela está inserida.

Consideraremos quatro aspectos essenciais pra compreendermos as distinções entre o idealismo e o materialismo dialético e, consequentemente, perceberemos as influências limitadoras do idealismo na filosofia pragmática de John Dewey para transformação do processo educacional, como segue:

\begin{tabular}{|c|c|}
\hline IDEALISMO & MATERIALISMO DIALÉTICO \\
\hline 1) Conciliação do pensamento com a realidade & 1) Homem modifica a realidade \\
\hline 2) Homem passivo & 2) Homem em ação \\
\hline 3) Comportamento reflexivo e contemplativo & $\begin{array}{l}\text { 3) Comportamento operativo } \\
\text { (ação, movimento) }\end{array}$ \\
\hline $\begin{array}{l}\text { 4) Sujeito da História - pensamento } \\
\text { Objeto/predicado - Homem }\end{array}$ & $\begin{array}{l}\text { 4) Sujeito da História - Homem } \\
\text { Objeto/ predicado - pensamento }\end{array}$ \\
\hline
\end{tabular}

A filosofia pragmatista é evolucionista e não revolucionária, pois sofre influência hegeliana idealista, constituindo as estruturas de sua filosofia - o progressismo -, negligenciando a própria economia a favor da importância do pensamento. No materialismo dialético, o pensamento será instrumento para a transformação da realidade. O Karl Marx em ação com seu pensamento em ação, salienta que a estrutura econômica é fundamental para o delineamento da estrutura educacional, consequentemente, se refletirá na própria ação pedagógica. Podemos verificar, como exemplos, os padrões distintos de socialização, os critérios questionáveis de avaliação, ênfases nas atitudes por parte dos alunos de obediência, passividade, resignação e outros. Neste quadro, a escola desenvolverá o seu papel de promover 
o pleno desenvolvimento humano, ou simplesmente, no processo capitalista será o agente da legitimação da estrutura de classes?

A sociedade em que John Dewey nasceu e desenvolveu suas reflexões sobre a problemática educacional norte-americana, é uma sociedade de classes, onde o poder político representa as grandes corporações financeiro-agro-industriais, cujos interesses estão voltados para a proteção das classes dominantes.

A formação de John Dewey ocorre neste contexto, os postulados de sua filosofia, embora avançados para as sociedades de classes, não atendem aos interesses da burguesia financeiro-agro-industrial, pois não exalta o consumo desenfreado e o mercado.

Dewey advoga que a escola deve fomentar a cooperação em vez da concorrência, baseada no amor e na solidariedade; enfatiza, que esses dois valores são mais importantes que a concorrência e o êxito pessoal, portanto, é a negação de um dos pilares da economia capitalista. Os valores ensinados na escola são os que melhoram o bem estar humano, num processo de fortalecimento do senso crítico, rejeitando qualquer tipo de individualismo e dando ênfase ao pensamento independente, à capacidade criadora e a um comportamento verdadeiramente humanista. Esta visão idealista subjetivista esconde a luta de classes, que se desenvolve em todas as sociedades capitalistas e justifica o apego do autor à democracia burguesa, em que a própria escola deve ser democrática para ensinar democracia. Para o pragmatismo os valores são relativos e não absolutos e imutáveis, conforme o idealismo.

O que está em jogo é a manutenção do status quo, em que $90 \%$ da população está condenada à pobreza, à miséria e à fome, enquanto $10 \%$ procurará manter o poder, assegurando o controle de $87 \%$ da riqueza mundial. Como consequência, as resistências ao progressismo das elites econômicas e religiosas, como ocorreu no Brasil em 1930, pois os conservadores não poderiam admitir educação laica, valores relativos, pessoas criativas, críticas, analíticas de suas realidades e transformadoras. Por outro lado, Dewey não reconheceu a luta de classes no processo social inviabilizando a sustentação de sua filosofia. Os limites do progressismo (BEVILAQUA, 2014, pp. 6-10) não foram suficientes para alterar, significativamente, a estrutura educacional de países seculares envolvidos em práticas educacionais compromissadas com o poder dominante, que assustado com qualquer manifestação de pensamento que possa abalar as condições estabelecidas em benefício de pequenas parcelas de famílias, que usufruem da injusta e desumana relação econômica de classes. Deste modo, procura-se obstaculizar qualquer manifestação de prática intelectual, que tenha probabilidade de alterar no futuro qualquer possibilidade de transformação social e política, que beneficie a totalidade da população mundial, principalmente no processo pedagógico. De acordo com o pensamento hegeliano, que enfatiza que as mudanças quantitativas, após determinado grau geram variações qualitativas (SODRÉ, 1983, p. 16), teríamos um grande contingente de pessoas reflexivas e conscientes, questionando e exigindo o equacionamento dos graves problemas, que afetam a humanidade e colocam em risco a sua própria sobrevivência e das demais espécies.

A educação com John Dewey, baseada em sua própria filosofia ou, por outra, em sua evolução, obrigou-se a indagar e descobrir, por qual método e qual o mais eficaz, de fazer o mais jovem assimilar o ponto de vista do mais velho, isto é, o homem, isoladamente perecível, fazer-se eterno, passando todo o acervo de conhecimentos e experiências adquiridos e cada vez mais vastos à humanidade imperecível. Há um 
perene esforço de renovação na vida, para a sua continuidade, o que torna a nutrição e a reprodução, para a vida fisiológica, o mesmo que a educação, para a vida social.

Essa educação vai se tornando quanto mais complexa, quanto mais desenvolvido o organismo social. Se a necessidade do aprendizado intencional é cada vez maior, também, uma separação indesejável e perigosa entre a experiência do jovem que se faz de maneira direta em seu meio social extracurricular, daquela obtida na escola, se faz sentir cada vez mais. Daí a importância do método. Da indagação do método, surge toda uma Escola fundamentada na vida no seu próprio ambiente característico de experiências constantes e fecundas, realmente ativa, com vivências em seu ambiente físico e social. Surge, aí, o Projeto como veículo para o método na escola de Dewey, uma escola realmente viva e ativa.

Dentro desse método foi sugerido, com oportunidade, e desenvolvido por vinte e nove alunos de 2a série ginasial, do Ginásio Estadual Pedro Bruno e do Colégio Estadual Olavo Bilac, em colaboração, um projeto, no qual trabalharam durante quatro meses, no levantamento da fauna litorânea da Ilha de Paquetá, procurando estabelecer as causas da distribuição irregular das espécies nos dois extremos da ilha.

A apresentação do que observaram e o resultado de suas pesquisas permitiram-lhes obter o segundo lugar em Ciências, na Primeira Feira Nacional de Ciências, e o primeiro lugar, na segunda Mostra Estudantil de Ciências da Guanabara (22 a 28 de setembro de 1969). O Projeto ficou dentro dos interesses imediatos da comunidade de Paquetá, abrangendo os aspectos de pesquisa científica e de natureza prática em seu aspecto econômico-social.

\section{II - LINHAS GERAIS DAS VÁRIAS ETAPAS DO PROJETO}

(1)- COMO E POR QUE

As condições materiais do Ginásio Estadual Pedro Bruno são mínimas, porém, a vivência espontânea dos educandos com a natureza e a dependência que toda a comunidade da ilha tem do equilíbrio biológico do meio, nos permitem aplicar técnicas didáticas de motivação, observação, incentivo e experimentação in loco, relacionando o estudo teórico com a vida real, através de pesquisas de campo, onde os alunos têm a participação ativa em trabalhos práticos, exposições orais de suas observações, discussões dirigidas pelos professores sobre problemas por eles encontrados. É fácil, nesse ambiente, criar as condições para manter a motivação do aprendiz, tornando-se este a figura mestra de todo o desenvolvimento do trabalho pedagógico. Cria-se, facilmente, a compreensão de que ainda não estão suficientemente preparados para resolver e dar soluções aos diversos problemas que afligem à sua comunidade, pois ainda carecem de orientação e aperfeiçoamento. A vida social exige do educando atitudes adequadas ao trabalho em grupo. A especial situação da Ilha de Paquetá facilita o interesse das atividades em grupamentos, corporificando e intensificando a elaboração do projeto.

As condições do Colégio Estadual Olavo Bilac favorecem aos trabalhos pedagógicos, dentro de uma concepção formal tradicionalista, no qual o professor se destaca como centro do processo numa relação inflexível de autoridade. No meio urbano, com a sobrecarga horária dos colégios, as aulas de ciências correm o risco de serem teóricas, expositivas, no máximo "experimentais”, isto é, “aulas práticas”. Apesar disso, o professor capaz de motivar e conduzir seus alunos através das etapas do processo 


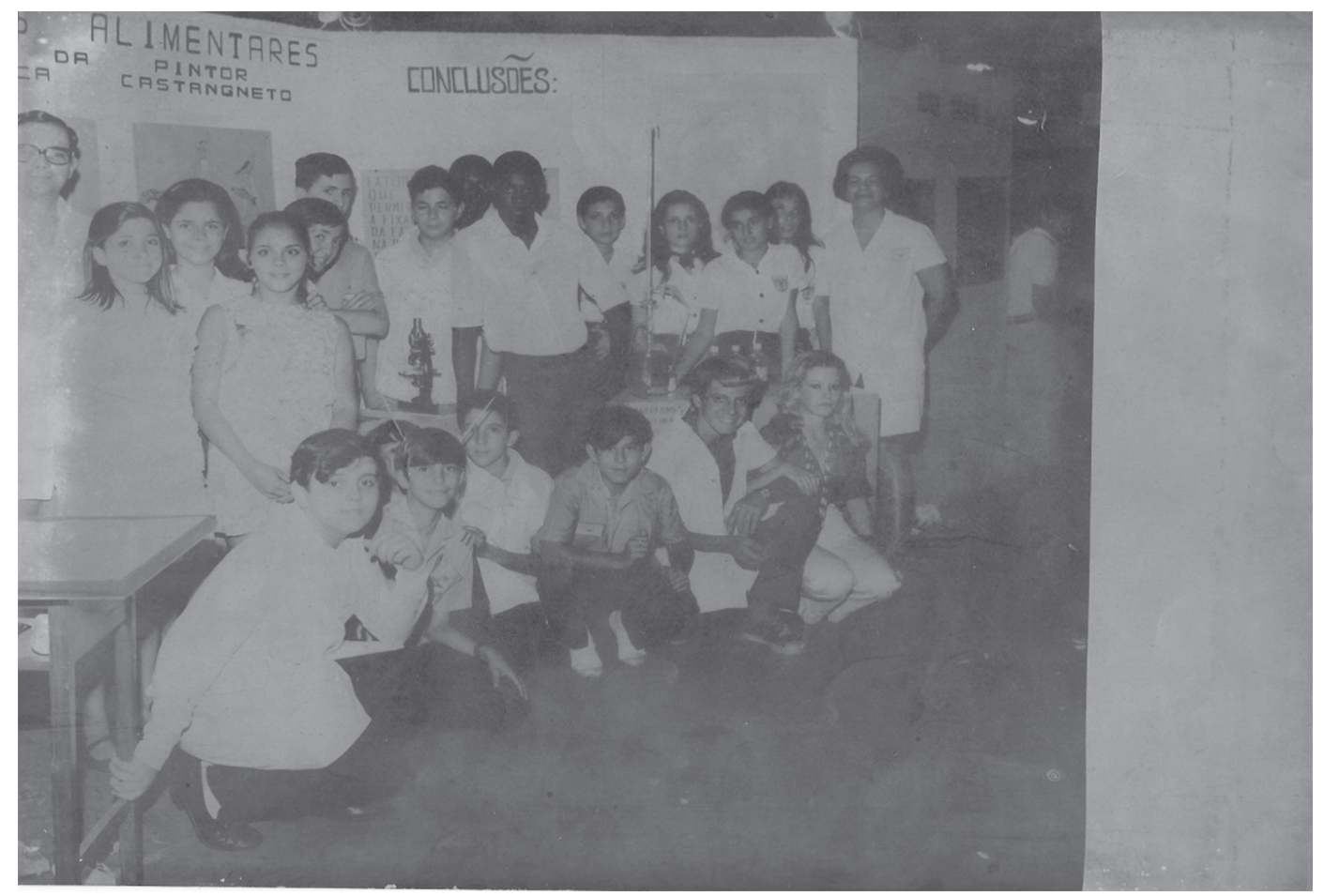

Alunos e professores participantes do projeto, I Feira Nacional de Ciências, Pavilhão de São Cristovão, Rio de Janeiro, RJ, 22 a 28 de setembro de 1969.

experimental consegue transformar o ensino de ciências em centro de discussões dos problemas da natureza da vida, especialmente, se iniciar o trabalho com turmas de primeira série.

No Colégio Estadual Olavo Bilac, contamos com laboratório e instalações adequadas. Em geral, os cursos de ciências apresentam, como característica, o desenvolvimento de uma parte teórica, acompanhada ou não, de uma sequência de aulas práticas, que são uma continuação da matéria em andamento; os trabalhos práticos, geralmente, são realizados pelo professor, como ilustração de suas aulas. Na verdade, estas aulas podem ser úteis como “informação", porém, deixam muito a desejar, quanto à formação do educando.

Os alunos dessa unidade escolar que participaram desse evento, desde a sua primeira aula de ciências no curso ginasial, depararam-se com problemas e foram desafiados e treinados em pesquisas, para solucioná-los, pela professora Maria Júlia da Costa Belém, a qual motivou os alunos a compartilhar, com os seus colegas de Paquetá, as buscas das causas e respectivas soluções aos quesitos apresentados no decorrer do trabalho. A união dessas duas unidades educacionais possibilitou efetiva sinergia para o desenvolvimento do projeto.

\section{III- MÉTODO DE TRABALHO}

O trabalho foi realizado por vinte e nove alunos, divididos, por eles próprios em cinco grupos, dos quais quatro com seis alunos e um com cinco. Consideramos que, para a formação ideal do educando, deverá ele ter experiência concreta de suas potencialidades em relação aos problemas que o desafiam, especialmente se trabalhar em 
grupo. Para que isso ocorresse, tivemos a preocupação de orientar cada responsável de grupo de trabalho, que funcionasse de modo ordenado e analisasse rigorosamente os dados obtidos, em cada observação ou experimentação. Este por sua vez, orientava os seus colegas.

\section{IV- RELATO SUCINTO dO TRABALHO}

Inicialmente, os grupos coletaram espécies animais fixados no litoral, observando sua distribuição e suas características peculiares. Surgiu, então, o primeiro problema: como classificá-las?

Com a orientação dos professores, os jovens observaram e anotaram as principais características de cada animal; consultaram livros didáticos e estabeleceram chave de classificação sistemática, bem simples, ao nível secundário, como segue:

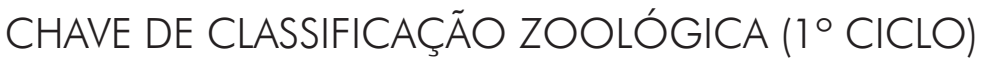

1 Animais de uma só célula, microscópicos, com ausência de tecidos diferenciados ... PROTOZOÁRIOS

2 Animais macroscópicos de várias células com tecidos diferenciados ... METAZOÁRIOS

2.1 Animais com ausência de esqueleto ósseo e cartilaginoso... (3) INVERTEBRADOS

2.2 Animais com esqueleto ósseo ou cartilaginoso presente. (4) VERTEBRADOS

3.1 Animais fixos aquáticos, corpo irregular com muitos orifícios e esqueleto constituído por espículas calcárias ESPONGIÁRIOS

3.2 Animais aquáticos com duas formas alternantes, pólipo e medusa, providos de órgãos de defesa (cnidoblastos) CELENTERADOS

3.3 Animais geralmente com formas estreladas, globosas, discoides, cilíndricas, corpo protegido por placas calcárias mais ou menos soldadas, locomovem-se por pés ambulacrários EQUINODERMOS

3.4 Animais de corpo mole e viscoso, não apresentam membros articulados e corpo segmentado, constituídos por conchas calcárias ... MOLUSCOS

3.5 Animais de corpo segmentado com pés articulados e revestidos de quitina ARTRÓPODES

3.6 Animais de corpo achatado com órgãos de fixação com ganchos quitinosos e ventosas de vida parasitária, com ausência de apêndices articulados, concha calcárias são de corpo mole, não apresentando aparelho digestivo PLATELMINTOS

3.7 Animais que não apresentam apêndices articulados e concha calcária, com corpo mole, cilíndrico e pontiagudo nas extremidades com aparelho digestivo e vida parasitária ASQUELMINTOS

3.8 Animais de corpo mole, alongado, formado por vários anéis segmentos, com ausência de apêndices articulados e conchas calcárias locomovem-se por cordas locomotoras ANELÍDEOS

3.9 Animais marinhos revestidos por túnica de celulose ... PROTOCORDADO

4 Animais que apresentam coluna vertebral com esqueleto ósseo ou cartilaginoso CORDADO 


\section{QUADRO COMPLEMENTAR DA CLASSIFICAÇÃO DOS ARTRÓPODES}

$\begin{array}{cll}\text { ANTENAS } & \text { N }^{\circ} \text { DE APÊNDICES } & \text { CLASSE } \\ 4 & 10 \text { ou mais } & \text { CRUSTÁCEO } \\ 2 & 6 & \text { INSETO } \\ 2 & 1 \text { par por segmento } & \text { QUILÓPODE } \\ 2 & 2 \text { pares por segmento } & \text { DIPLÓPODE } \\ - & 8 & \text { ARACNÍDEO } \\ & & \end{array}$

1. Animais envolvidos por uma concha calcária (univalvos), com o pé muito desenvolvido e achatado GASTRÓPODES

2. Animais envolvidos por duas conchas calcárias (bivalvos), acéfalos PELECÍPODES

3. Animais com conchas internas, com olhos e boca circundada por tentáculos CEFALÓPODES

\section{CHAVE CLASSIFICATÓRIA DOS EQUINODERMOS}

1. Animais marinhos, vida livre, corpo em forma de estrelas ... ASTERÓIDES

2. Animais marinhos, vida livre com um disco central e cinco braços finos e longos com forma serpentóide OFIURÓIDE

3. Animais marinhos com corpo globoso, carapaça calcária e espinhos, alguns com placas calcárias soldadas, formando uma cápsula que protege o corpo, forma achatada EQUINÓIDE

4. Animais de corpo mole com tentáculos à boca, corpo cilíndrico com placas calcárias microscópicas HOLOTURÓIDE

5. Animais fixos ao substrato por um pedúnculo, forma arbórea, com cinco braços longos e finos, boca e ânus na região superior CRINÓIDE

As chaves foram de tal maneira simplificadas que puderam ser utilizadas não só no trabalho, como também nas aulas de ciências, quebrando com as memorizações repetitivas, até então contumazes, e assegurando um processo qualitativo do ensino-aprendizagem, em que a observação e o manuseio possibilitam ao educando compreender as estruturas anatômicas, as diferenças adaptativas ao meio ambiente dos animais, facilitadoras da percepção de que a própria evolução das espécies é um processo.

Ao mesmo tempo, os grupos observaram a distribuição da fauna no litoral da ilha. Terminado o levantamento nas praias de um dos extremos, os educandos foram para a Praia da Imbuca. Após uma manhã de trabalho quase inútil, coletando com dificuldade apenas quatro espécies, vieram os questionamentos do fato de ter o local tão 
poucos exemplares. Na praia do outro extremo foi encontrado um grande número de espécies. Por que aqui haveria uma diferença tão grande de quantidade? Que fatores poderiam contribuir para isso?

Nas discussões preliminares ao levantamento das hipóteses, os alunos estabeleceram, como um dos fatores preponderantes, a quantidade de alimentos. Observaram, então, os alimentos dos quais os animais viviam. Foi assim que um dos líderes veio nos perguntar: "Professor, tem que haver alguma coisa na água que os peixes e os outros animais comam.... O que é?" Devolvemos o problema para que refletisse e interagisse com os demais colegas. No dia seguinte, novamente fomos procurados pelo líder, que buscava saber se a fosforescência que tinha observado à noite, sobre as águas, teria alguma relação com isso. Pela segunda vez, devolvemos a questão, orientando-os para que recolhessem o material e o examinassem. Assim, foi descoberto o plâncton por alunos do segundo ano ginasial. $O$ trabalho seguinte foi, apenas, anotar "quem come quem", isto é a cadeia alimentar.

Quando recolhemos os relatórios dos grupos, estávamos diante de duas cadeias alimentares levantadas por observação direta pelos discentes. Com a cadeia alimentar estabelecida, foi possível levantar hipóteses: a quantidade de alimento e oxigênio na Praia Pintor Castagnetto e proximidades (onde foi encontrado grande número de espécies) seria maior que na Praia da Imbuca? Como testar e comprovar tal hipótese?

Pelo processo de Winkler, usado pelo Laboratório de Análise da Água - Sursan -, os educandos determinaram as taxas de oxigênio nas duas praias. Chegaram à conclusão de que somente um fator não explicaria o problema encontrado, porque observaram apenas uma pequena diferença de oxigenação entre as duas medições (Pintor Castagnetto e Imbuca). Observando as características geográficas e ecológicas de cada praia, notaram a existência, na praia Pintor Castagnetto de:

a) Uma enseada protegendo o litoral da ação das marés e permitindo a fixação de espécies vegetais que atraem espécies animais;

b) Menor profundidade e maior luminosidade, influindo na maior oxigenação em função da fotossíntese das algas verdes;

c) Ausência de óleo na superfície da água o que influenciaria a luminosidade e a própria oxigenação, conforme citado acima;

d) Ausência de grandes predadores.

Enquanto isso, na Imbuca, o litoral é reto e abrupto, sofrendo violenta ação das marés. Está próximo a um dos pontos de maior profundidade da região e voltado para depósitos de óleos e locais de lavagens de navios na Baía de Guanabara. Nota-se, ainda a presença de grande número de animais predadores no litoral. É impressionante o número de calangos (lagartos) que deixam as encostas e vão buscar os alimentos na Praia da Imbuca.

De início foram focalizados dois pontos da ilha: a Praia da Imbuca e a Praia Pintor Castagnetto e os dados levantados não foram suficientes para o equacionamento da solução do problema. Os professores se reuniram com os líderes e seus respectivos grupos, informando-os da necessidade de se aumentar o campo de pesquisa para se obter um quadro mais real da diversidade bioecológica da localidade. Colocada em votação a proposta foi aceita por unanimidade. 


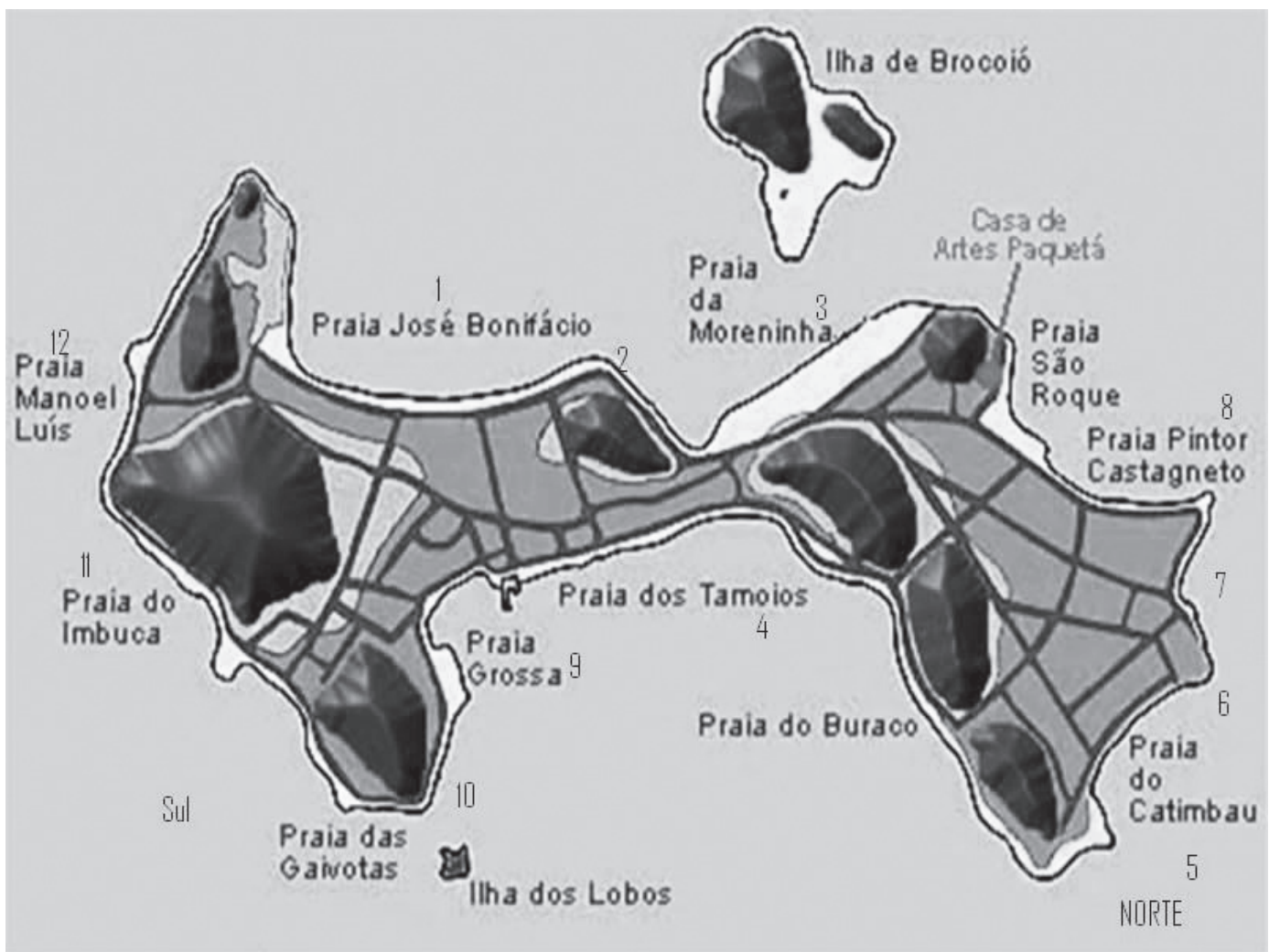

Mapa da llha de Paquetá

Os grupos retornaram ao trabalho agora nas praias Manuel Luiz, Marechal Floriano, e quase nada foi encontrado, e observaram as praias laterais, José Bonifácio e Grossa, que apresentaram ausência quase completa de exemplares. Quanto ao outro extremo foram visitadas as praias Coqueiros, Moreninha e Dr. Aristão. Na Praia dos Coqueiros foram encontradas inúmeras espécies fixadas ao litoral e observados insetos e vestígios de algas marinhas. Quanto às praias da Moreninha e Dr. Aristão, praias de elevadas demandas turísticas, não foram constatadas presenças significativas de animais, talvez, pela ação predatória dos visitantes.

Na Praia Pintor Castagnetto foi levantada, depois de um mês e meio de observação, a pirâmide alimentar dos animais vegetarianos como alguns ouriços e moluscos e da estrela do mar (Patiria sp), a qual se alimentava de animais vegetarianos, como alguns moluscos e ouriços do mar, além de se alimentar de onívoros, como a barata d água.
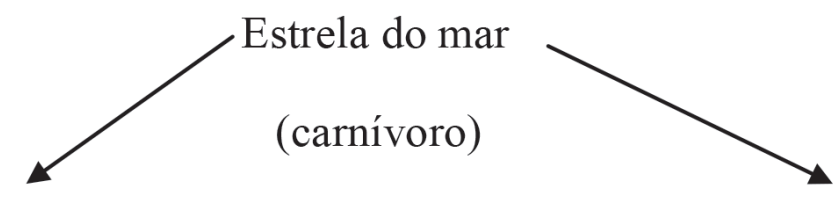

Barata d água (onívoro)
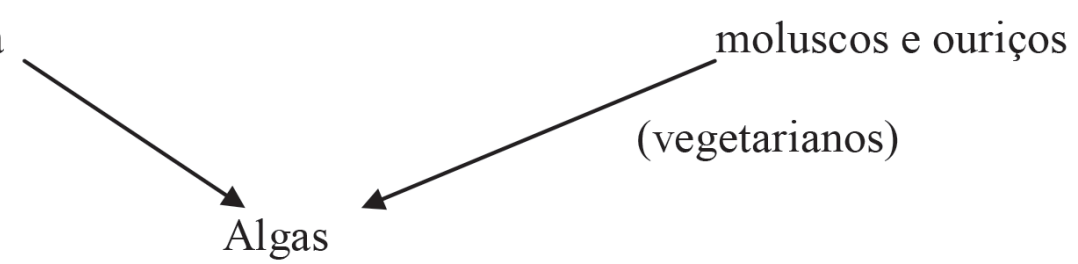
Ao dissecarem os ouriços do mar, foram encontrados restos de algas, o que confirmou serem consumidores primários, vegetarianos, enquanto os consumidores secundários são os animais carnívoros. A base da pirâmide corresponde aos seres produtores fotossintéticos, algas, fitoplâncton e o plâncton. Os novos dados consolidaram os anteriores, o que reforçou a necessidade de se localizar os fatores determinantes desta dispersão irregular.

Os líderes foram ao laboratório de análise de água da Sursan (Superintendência de Saneamento do Estado do Rio de Janeiro) e ao constatarem, através de exame comparativo dos quadros do órgão oficial relativos à análise da água da baía de Guanabara, em várias datas, perceberam que somente o oxigênio não poderia justificar a dispersão da fauna marinha; isso porque fatores como a circulação da água e a própria temperatura podem modificar, bruscamente, a quantidade de oxigênio existente na água, basta um navio descarregar óleo em excesso para que todo o equilíbrio se altere, influindo até mesmo a profundidade. Observando-se o mapa da Ilha de Braço Forte (onde a oxigenação é quase sempre zero) e as praias da Imbuca e Manuel Luiz, já que nesse ponto há grande profundidade, a difusão do oxigênio seria muito difícil, assim, como também a intensidade luminosa reduz-se bruscamente, impedindo a existência de algas a partir de mais ou menos dois metros de profundidade, ao contrário do que o corre nas proximidades da Praia Pintor Castagnetto, onde também se observam outros fatores capazes de possibilitar a instalação de uma fauna mais variada, como segue:

1. A iluminação é muito maior devido ao fato de ocorrer menor quantidade de óleo na superfície, permitindo assim a instalação de vegetais clorofilados, que atraem outras espécies;

2. As marés, durante o período de maior fluxo (lua cheia e lua nova), não castigam tanto o litoral das praias Pintor Castagnetto, Lameirão e Coqueiro, localizadas em enseadas protetoras, que permitem a melhor instalação da maioria das espécies, o que não acontece do lado oposto;

3. Maior quantidade de alimentos (algas e detritos animais encontrados no substrato, devido à pequena profundidade e às enseadas, o que não ocorre nas praias do outro extremo da ilha, que são completamente abertas e sujeitas à ação das correntes).

4. Ressaltamos mais uma vez a menor existência de animais predadores nestes locais.

A estrutura da cadeia alimentar da fauna marinha se apresenta conforme segue:

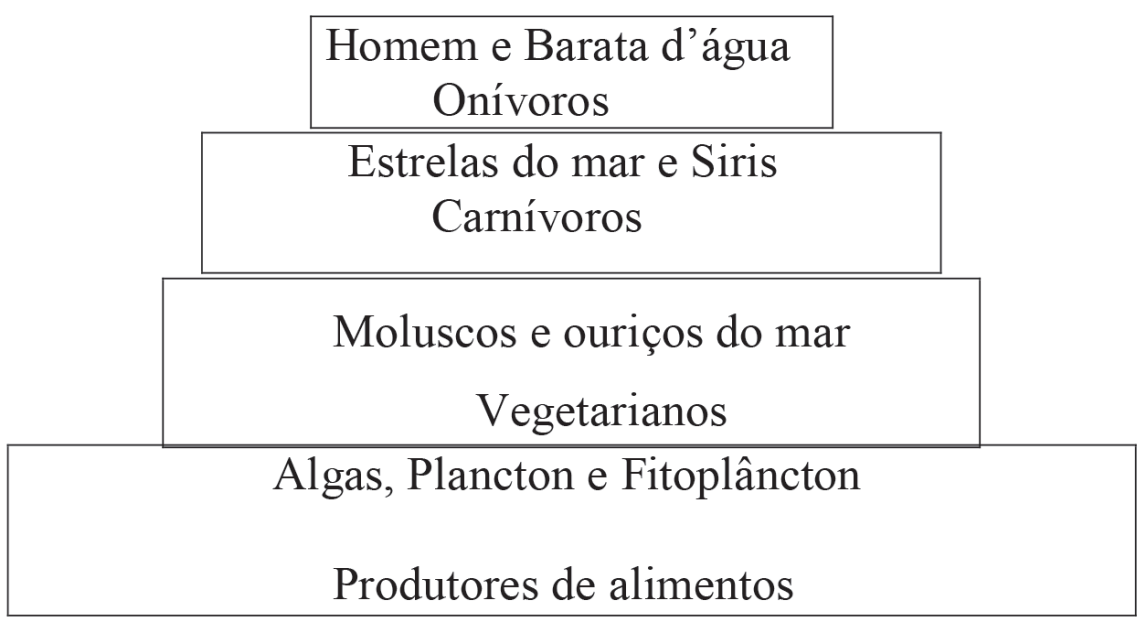




\section{V- DOS OBJETIVOS E DAS CONCLUSÕES}

Os objetivos alcançados conseguiram incentivar os educandos a preservar e a conservar o habitat natural do Homem, estabelecendo na prática, a relação entre a ciência estudada na escola e a vida real do Homem (o Homem e o seu meio).

A importância de ser preservada a fauna e a flora é fundamental, pois caso ocorra a sua destruição haverá um desastrosa falta de equilíbrio que poderá acarretar prejuízos incalculáveis, não só de imediato, como também para gerações futuras. Como exemplo a importância econômica da pesca para a comunidade paquetaense.

Com o desaparecimento progressivo do produto vital do pescador no futuro haverá problemas para a comunidade do ponto de vista econômico-social.

Vários fatores à época influíram para que ocorresse uma extinção de espécies na Baía de Guanabara. Ocorria um alto índice de poluição causado pelas lavagens dos navios, que jogavam detritos no mar, bem como, a presença das desembocaduras das refinarias de Manguinhos, Duque de Caxias, fábrica de gás e depósitos espalhados pela baía, criando um meio desfavorável à sobrevivência das espécies aquáticas. Além disso, verifica-se a destruição sistemática feita pelo próprio pescador que, sem consciência de sua atitude, elimina, indiscriminadamente, através de bombas de dinamite, as espécies.

A verdade é que não se procura trazer as soluções dos graves problemas que assolam a baía, mas sim, despertar a consciência da população na preservação da fauna e da flora da região.

Os alunos envolvidos no projeto sugeriram que deveriam apontar rumos para diminuir e combater a progressiva ação destruidora do homem no equilíbrio ecológico da natureza. Organizado o estande para a exposição, foi incluído o item 8 com as sugestões dos grupamentos para o combate à poluição na Baía de Guanabara.

\section{VI-CONCLUSÕES}

$1^{\circ}$ Foi-nos possível perceber a possibilidade de haver na escola secundária um currículo integrado,visando à formação do educando, despertando nele o interesse para problemas de ordem econômica, social e cultural;

$2^{\circ}$ Desenvolveu-se uma série de atividades curriculares, que se tornaram também recreativas, possibilitando melhor aproveitamento do que nas aulas usuais;

$3^{\circ}$ As atividades culturais e sociais, paralelas à pesquisa científica, estimulando-lhes a observação, a experimentação e a análise lhes permitiram desenvolvimento intelectual no sentido de investigação científica e de criatividade responsável;

$4^{\circ}$ Os alunos participantes do projeto orientados na filosofia pragmática e no método científico, possibilitaram-nos estabelecer uma escola viva na qual padrões consagrados não se estabeleceram;

$5^{\circ}$ Foi conseguido, durante o desenvolvimento dos trabalhos, uma escola de fato integrada na comunidade, refletindo, estudando e procurando trazer soluções aos seus problemas.

Sem entrarmos na discussão da maior ou menor validade e rendimento dos processos e técnicas de ensino, dentro de um método geral, mas convictos da necessidade de se dar ênfase crescente à orientação das possibilidades individuais, à liberdade do educando de se desenvolver, a ajudá-lo na aquisição de conhecimentos, obtendo 
que ele mesmo possa agir e fazer a própria vivência, não o separando da vida, nem o sufocando, a enriquecê-lo, sem deformá-lo, e ao respeito de sua personalidade, constataremos que o "projeto" é uma técnica feliz, enquadrado numa metodologia resultante do encadeamento de um raciocínio filosófico, capaz de abranger as contradições e perplexidades do mundo moderno.

\section{VII - APLICAÇÕES}

Os educandos, durante o desenvolvimento do projeto, impressionaram-se com o problema da poluição da água, localizaram suas causas, e resolveram fechar os trabalhos com sugestões visando minorar problema tão grave ao equilíbrio biológico da baía de Guanabara; tais como:

- proibição de lavagens de navios;

- proibição de descargas dos lixos nas águas da baía;

- saneamento dos rios que deságuam na baía levando resíduos industriais e detritos domésticos e de animais;

- transferência dos depósitos de óleos e terminais de oleodutos;

- educação do povo sobre a necessidade de se respeitar a natureza em seu indispensável equilíbrio vital à sobrevivência da espécie humana.

\section{Referências bibliográficas}

OZMON, Howard. Filosofia da Educação. Rio de Janeiro: Editora Zahar, 1975. BEVILAQUA, Aluisio Pampolha. John Dewey e a Escola Nova no Brasil, Ciência E Luta de Classes, vol. 8, n. 9, pp. 5-14.

HEGEL, G. W. F. Ciência da Lógica. Excertos. São Paulo: Barcarolla, 2012. KNELLER, George F. Introdução a Filosofia da Educação. Rio de Janeiro: Editora Zahar, 1974.

SARUP, Madan. Marxismo e Educação. Rio de Janeiro, Editora Zahar, 1978. SODRÉ, NELSON WERNECK. 4a edição. História da Burguesia Brasileira. Petrópolis: Editora Vozes, 1983. 
ANEXO 1

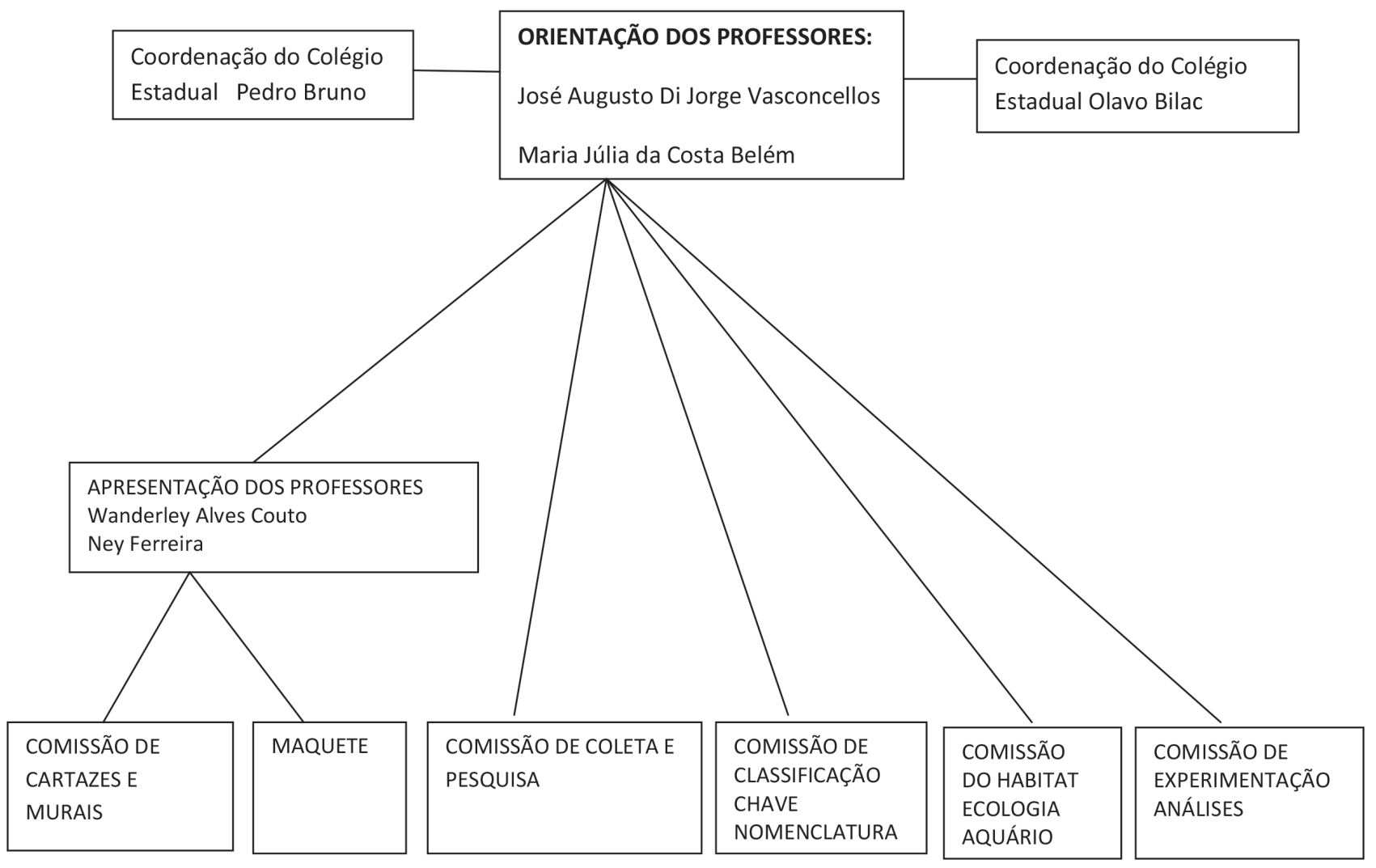




\section{ANEXO II}

PLANO DE TRABALHO

I - INTRODUÇÃO

DA ORGANIZAÇÃO E MÉTODO DE TRABALHO

DOS OBJETIVOS E DAS CONCLUSÕES

I I - DESENVOLVIMENTO DO TRABALHO

$1^{\circ}$ OBSERVAÇÃO

2० DEFINIR PROBLEMA

$3^{\circ}$ HIPÓTESE E EXPERIMENTAÇÃO

$4^{\circ}$ PESQUISA BIBLIOGRÁFICA

5० APLICAÇÃO

I I I- EQUIPE DE TRABALHO

ESTRUTURAÇÃO DE GRUPOS DE TRABALHOS;

DEFINIÇÃO DE LÍDERES DE GRUPOS;

DEFINIÇÃO DAS TAREFAS E PRAZOS.

IV- ANEXOS

\section{ANEXO III}

\section{Relação dos educandos que participaram do Projeto}

Fauna das praias da Ilha de Paquetá e problemas ecológicos da comunidade

GINÁSIO ESTADUAL PEDRO BRUNO

Diretor: Prof. Tharceu Nherer

Alunos

Alcilino Jorge Antunes

Carlos Alberto Pinto Lisboa

Deia Pereira dos Santos

Eliane Cabral Fernandes

Elza de Souza Pessoa

Francisca Guimarães

Fátima Palha de Oliveira

José dos Santos

Maria Elizabeth Delgado

Maria Lívia Machado Chaves

Maria Lúcia Coutinho

Maria Marques Leitão 
Maria Olinda Costa Freitas

Péricles Palha de Oliveira

COLÉGIO ESTADUAL OLAVO BILAC

Diretor Prof. Murilo Pessôa

Alunos

Aurélio A. e Souza

Carlos Alberto Dias

Carlos Eduardo

Cristina Lucena do Val

Fernando Oliveira dos Santos

Francisco Antônio Scaramelo

Hélio Henriques Moraes

Hélida Lopes

Jansen Q. Vilela

Laudelino A. Nascimento

Marcus Barroso Pereira

Margareth R. Meinick

Nádia Jorge Seixas

Regina Célia Guters

Sônia Maria Moreira 


\section{ANEXO IV}

CADEIA ALIMENTAR DA PRAIA PINTOR CASTAGNETTO (PAQUETÁ) (JULHO-AGOSTO DE 1969)

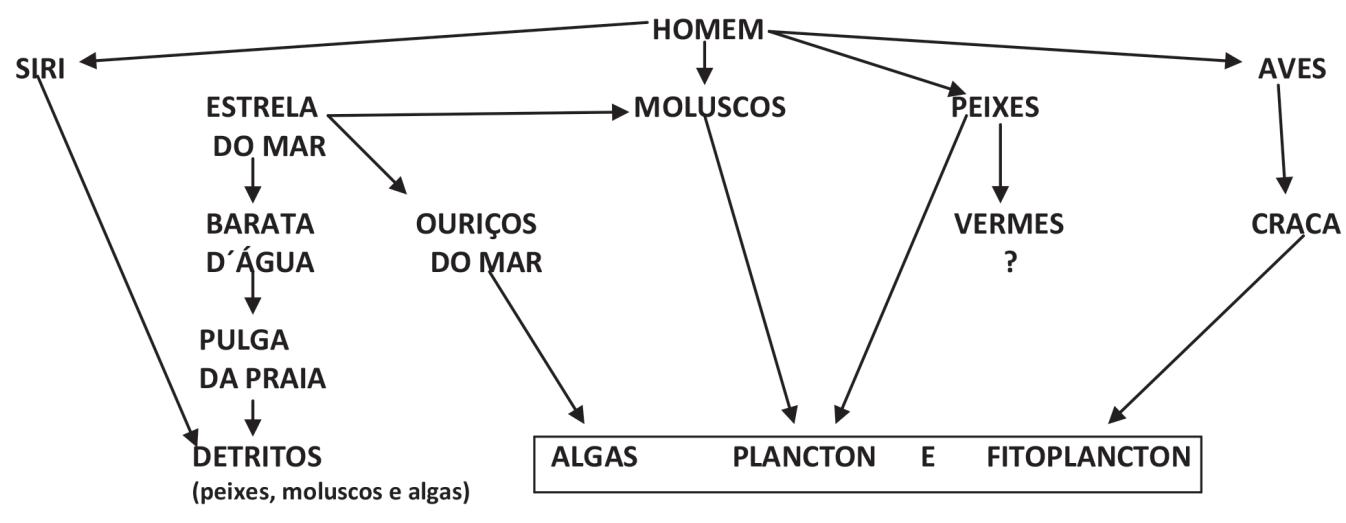

CADEIA ALIMENTAR DA PRAIA DA IMBUCA- (PAQUETÁ) (JULHO-AGOSTO DE 1969)

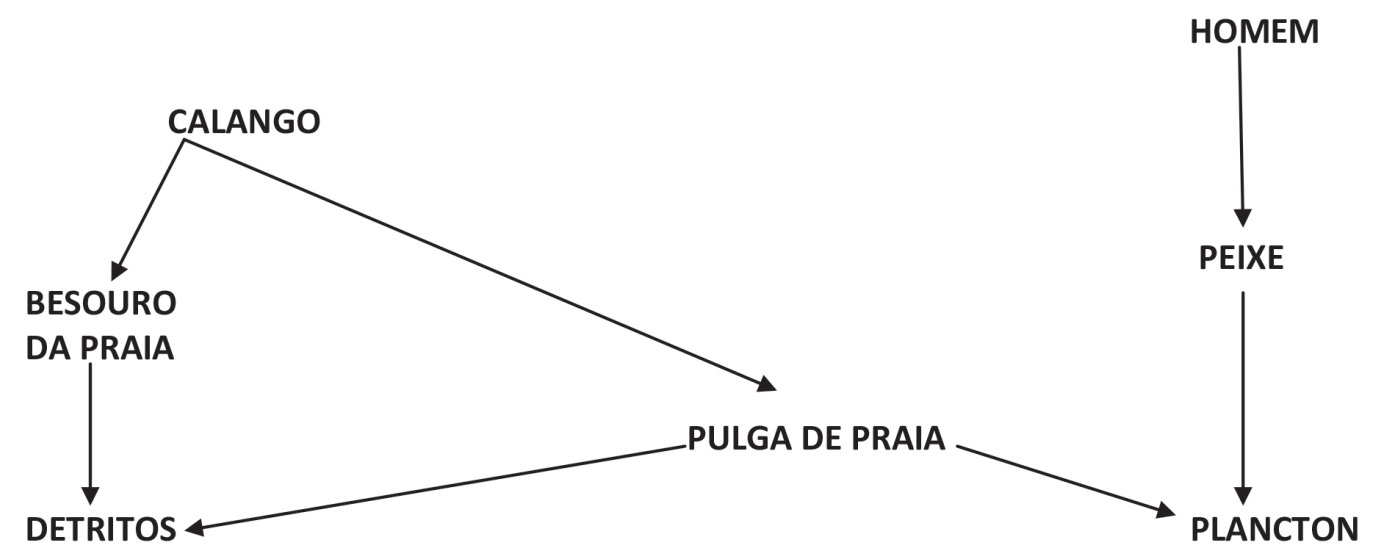




\section{ANEXO V}

FAUNA DAS PRAIAS DA ILHA DE PAQUETÁ- JULHO-AGOSTO DE 1969

\begin{tabular}{|c|c|c|c|}
\hline LITORAL & $\begin{array}{l}\text { ESPÉCIE E } \\
\text { NOME VULGAR }\end{array}$ & RAMO & PRAIA \\
\hline $\begin{array}{l}\text { SUPRA LITORAL } \\
\text { (rochas e partes arenosas, } \\
\text { expostas) }\end{array}$ & $\begin{array}{l}\text { - Lygia sp. } \\
\text { (barata d'água) } \\
\text {-Littorina } \\
\text { (L. flava) } \\
\text { - Mecistomela sp. } \\
\text { (barata do coqueiro) } \\
\text { - Calango } \\
\text {-Pulga da praia }\end{array}$ & $\begin{array}{l}\text { - Artrópode } \\
\text { - Molusco } \\
\text { - Artrópode } \\
\text { - Vertebrado } \\
\text { - Artrópode }\end{array}$ & $\begin{array}{l}8.7 .6 .5 .11 \\
8 \\
8 \\
8.11 \\
8.11 \\
\end{array}$ \\
\hline $\begin{array}{l}\text { Médio Litoral } \\
\text { (zonas em que predominam } \\
\text { as Tetraclitas ou sujeitas a } \\
\text { variações de marés) }\end{array}$ & $\begin{array}{l}\text { - Craca } \\
\text { (Tetraclita sp.) }\end{array}$ & -Artrópode & Todas as praias, exceto a 9. \\
\hline $\begin{array}{l}\text { INFRA LITORAL } \\
\text { (zonas permanentemente } \\
\text { cobertas pelas águas) }\end{array}$ & $\begin{array}{l}\text {-Cymatium sp. } \\
\text {-Actinea } \\
\text { (Bunodosoma sp.) } \\
\text {-Ouriços do mar } \\
\text { (Litechinus e Paracentropus sp.) } \\
\text {-Estrela do mar (Patiria sp.) } \\
\text {-Strombus sp. } \\
\text {-Mexilhão (Mytilus sp.) } \\
\text {-Siri } \\
\text { - Cavalo Marinho } \\
\text { (Hipocampus sp.) } \\
\text { - Mija-mija } \\
\text { - Peixes }\end{array}$ & $\begin{array}{l}\text {-Molusco } \\
\text {-Cnidário } \\
\text {-Echinoderma } \\
\text {-Echinoderma } \\
\text {-Molusco } \\
\text {-Molusco } \\
\text {-Artrópode } \\
\text {-Vertebrado } \\
\text {-Protocordado } \\
\text {-Vertebrado }\end{array}$ & $\begin{array}{l}7 \\
\text { Todas as praias } \\
6.7 .8 \\
\text { Todas as praias } \\
7.8 \\
8 \\
6.7 .8 \\
7.8 \\
6.7 .8 \\
\text { Todas as praias }\end{array}$ \\
\hline
\end{tabular}




\section{ANEXO VI}

\section{APRESENTAÇÃO DO TRABALHO NA I FEIRA NACIONAL DE CIÊNCIAS E NA II MOSTRA DE CIÊNCIAS DA GUANABARA-1969}

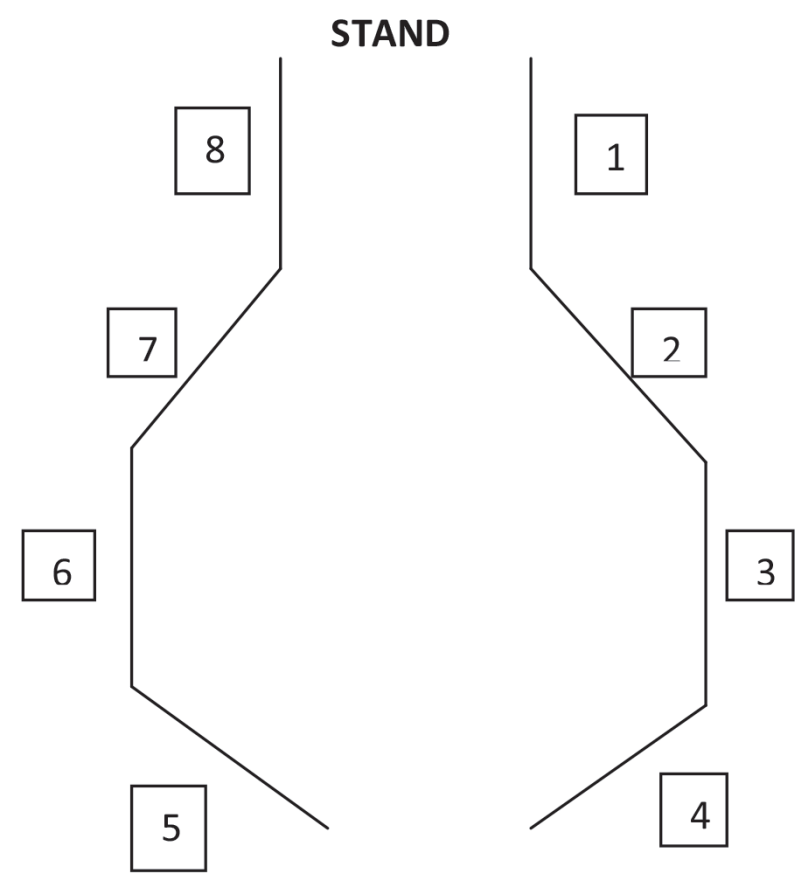

1. Apresentação quanto à natureza do trabalho

2. Animais coletados e classificados (chave sistemática)

3. Curiosidades (fosforescência, caracterização das carapaças calcárias)

4. Reconstituição do litoral, com os animais de cada região (aquário)

5. Mapa da ilha com a distribuição da fauna-maquete

6. Cadeia alimentar e plâncton (microscópio)

7. Dosagem de oxigênio e mapa da ilha, com determinação de profundidade. Fatores que permitiram maior número de espécies em um dos extremos da ilha (bureta, reativos químicos, frascos especiais para coleta de água e pipetas).

8. Sugestões para combate à polvição da água. 